\title{
Development of methods for introducing hybrid progeny of Malus sieboldii Rehd. at in vitro conditions
}

\author{
Roman Papikhin ${ }^{1, *}$, Svetlana Muratova ${ }^{1}$, Maksim Dubrovsky ${ }^{1}$, and Elena Grigoryeva ${ }^{1}$ \\ ${ }^{1}$ Federal State Budgetary Education Institution of Higher Education «Michurinsk State Agrarian Uni- \\ versity», 393760, Russia, Michurinsk, Internatsionalnaya str., 101
}

\begin{abstract}
The paper provides data on the use of the Malus sieboldii Rehd. as a genetic donor of economically valuable traits in breeding low-vigorous clonal apple rootstocks. The method of embryo culture is proposed as a way to increase the efficiency of distant crosses. The studies were carried out using seeds obtained in three combinations of crossing (M. sieboldii $\mathrm{x}$ Malysh Budagovskogo, M. sieboldii x 60-160, M. sieboldii x 76-3-6). As sterilizing agents when introduced into culture in vitro, we used industrial disinfectant «Belizna (Whiteness)», the sanitizer «Ecocid C»+ «Belizna» and the sanitizer «BioPag $\mathrm{C} »+\langle$ Belizna». It was found that additional pretreatment with «Ecocid $\mathrm{C} »(1.0 \%)$ and "BioPag C" $(0.4 \%)$ for 50 minutes before using the disinfectant «Belizna» contributes to the production of sterile explants up to $61.5 \%$ compared to the control. The best results were obtained when combine using «Ecocid $\mathrm{C} »(1.0 \%, 50 \mathrm{~min}$.) and «Belizna» $(50 \%, 5 \mathrm{~min}$.). After 28 days, due to the low number of developing embryos, the method of dissection of a part of the cotyledons of hybrid seeds was used. As a result, up to $65.3 \%$ of hybrid plants were obtained, compared to $4.2 \%$ of the control.
\end{abstract}

\section{Introduction}

For the selection of clonal apple rootstocks, the problem of obtaining forms, resistant to negative biotic and abiotic factors of the environment, has arisen in recent decades.

Plants of Malus sieboldii Rehd. were used as a promising genetic donor of economically valuable traits in breeding new apple rootstocks [1-2].

Malus sieboldii Rehd. belongs to the genus Malus, section Sorbomalus, series Toringonae (Rehd.) This species is of ancient origin. The species of the Sorbomalus section formed in the Tertiary period in Central and East Asia, the natural introduction and selection has led to a high polymorphism of the Malus sieboldii species, which is expressed not only phenotypically, but also genetically.

Since this species is evolutionarily old and quite polymorphic, there are conflicting data in the literature on the genetic characteristics of its representatives. According to B. Liu and colleagues [3], the endemic species of China is a triploid $(2 n=51)$.

\footnotetext{
* Corresponding author: parom10@mail.ru
} 
According to Dubrovsky M.L., Papikhin R.V. [4], the apomictic forms of M. sieboldii Rehd. are tetraploids $(2 \mathrm{n}=68)$.

The study of the cytogenetic features of $M$. sieboldii Rehd. from the genetic collection of the Michurinsk State Agrarian University showed that this species form is a mixoploid and contains 34 and 51 chromosomes in the nuclei of somatic cells $(2 \mathrm{n}=2 \mathrm{x}, 3 \mathrm{x}=34,51)$ [4-5].

Based on many years of breeding work on obtaining low-vigorous clonal apple rootstocks at the Michurinsk State Agrarian University, the problem of obtaining hybrid progeny of $M$. sieboldii Rehd. in the traditional way - by sowing seeds was clearly indicated. Different stratification schemes and cultivation conditions at the stage of seed germination practically did not give a positive result.

We supposed that this is due to the cytogenetic features of this species form. In crosses as one of the parents, in addition to Malus sieboldii Rehd., different rootstock forms took part, which represent complex interspecific hybrids. These rootstocks were created with the participation of 5 species of the genus Malus, which to a certain extent complicates the formation of male germ cells and negatively affects the fertilization of the macrospore.

However, single hybrid genotypes, obtained from the pollination of Malus sieboldii Rehd. by pollen of dwarf red-leaved rootstock forms, have a high regenerative potential [6] and resistance to diseases [2]. Similar results were obtained by other researchers [7-12].

Thus, obtaining hybrid progeny in some forms of $M$. sieboldii Rehd. is complicated and requires additional use of various breeding methods, primarily tissue culture. The culture of embryos with distant hybridization has been known for a long time, and at the present stage a lot of methods have been developed to increase the efficiency of obtaining hybrid progeny [13-15].

In this regard, the aim of the research is to optimize embryo culture methods for obtaining interspecific hybrids of M. sieboldii Rehd.

\section{Objects and methods}

The biological objects of research were hybrid apple seeds obtained from crossing $M$. sieboldii Rehd. (as female parent) with red-leaved dwarf rootstocks bred at the Michurinsk State Agrarian University (combination $1-$ M. sieboldii x Malysh Budagovskogo; $2-M$. sieboldii $\times$ 60-160; $3-$ M. sieboldii $\times$ 76-3-6). All the paternal forms that took part in the crosses have anthocyanin coloration of leaves and shoots. This trait serves as a marker for identifying apomictic genotypes of M. sieboldii (without anthocyanin coloration) and their further culling.

The seeds were isolated from ripe fruits, previously kept for 2-3 months at a temperature of $+4^{\circ} \mathrm{C}$.

The following schemes were used to sterilize explants:

1) industrial disinfectant «Belizna» $\left(\mathrm{NaOCl} \cdot 5 \mathrm{H}_{2} \mathrm{O}\right.$ - sodium hypochlorous acid $)+$ distilled water $(1: 1)$. Exposition 5 minutes. Three times washing with autoclaved distilled water (control);

2) sanitizer «Ecocid $\mathrm{C} »(1.0 \%)$, exposure 50 minutes. After it: industrial disinfectant «Belizna» + distilled water $(1: 1)$, exposition 5 minutes. Three times washing with autoclaved distilled water;

3) sanitizer «BioPag $\mathrm{C} »(0.4 \%)$, exposure 50 minutes. Industrial disinfectant «Belizna»+ distilled water (1:1). Exposition 5 minutes. Three times washing with autoclaved distilled water.

«Ecocid $\mathrm{C}$ » is a complex disinfectant containing $500 \mathrm{mg}$ of potassium peroxomonosulfate (triple salt) as an active ingredient in $1 \mathrm{~g}$. It contents as auxiliary components: surfactant sodium dodecylbenzenesulfonate, organic acids (malic, sulfamic), inorganic buffer 
systems (sodium chloride, sodium polyphosphate). «Ecocid C» has a wide spectrum of antimicrobial action against bacteria, viruses and fungi.

Antimicrobial agent «BioPag $\mathrm{C}$ » is used for cleaning and disinfection. Its active ingredient is polyhexamethylene guanidine hydrochloride, $\mathrm{pH}$ of a $1 \%$ solution of 8.0-105.

For the cultivation in vitro of seeds at the stage of introduction, we used the mineral base of the nutrient medium MS [5], plant growth regulators were added to the medium: 6benzylaminopurine (6-BAP) - 1-2 mg/l, gibberellic acid (HA) - 0.2-1 mg/l, $\beta$-indolyl-3butyric acid (IBA) $-0.1-0.2 \mathrm{mg} / 1$ or $\beta$-indoleacetic acid (IAA) $-0.2-0.5 \mathrm{mg} / \mathrm{l}$.

After planting on a nutrient medium, the seeds were transferred to a culture room with a temperature of $24 \pm 2^{\circ} \mathrm{C}$, an illumination of $2000-2500$ lux and a photoperiod of $16 \mathrm{~h}$ day / 8 $\mathrm{h}$ night.

After 4 weeks of cultivation in vitro, about $1 / 3$ of the seed was cut off with a scalpel from the side of the cotyledons.

The development of embryos was assessed on a point scale: 1 - lack of growth; 2 greening and disclosure of cotyledon leaves; 3 - bud germination and leaf rosette formation; 4 - formation of a well-developed shoot with a root.

\section{Discussion}

After the introduction of hybrid apple seeds in sterile conditions, the presence of fungal infection was recorded on the $6^{\text {th }}$ day after planting. Bacterial infection manifested itself on the $12^{\text {th }}$ day, and individual explants with signs of infection were detected in the next 18 days (Table 1).

Table 1. Infection of hybrid seeds with M. sieboldii depending on the combination of crossing

\begin{tabular}{|c|c|c|c|c|}
\hline \multirow{2}{*}{$\begin{array}{c}\text { Sterilization } \\
\text { option }\end{array}$} & \multirow{2}{*}{$\begin{array}{l}\text { Sterile ex- } \\
\text { plants, \% }\end{array}$} & \multicolumn{3}{|c|}{ Infected explants, \% } \\
\hline & & $\begin{array}{c}\text { amount from } \\
\text { sown, } \%\end{array}$ & $\begin{array}{l}\text { bacterial } \\
\text { infection }\end{array}$ & fungal infection \\
\hline \multicolumn{5}{|c|}{ Malus sieboldii x Malysh Budagovskogo } \\
\hline 1 (control) & 61,5 & 38,5 & 60,0 & 40,0 \\
\hline 2 & 94,4 & 5,6 & 0 & 100 \\
\hline 3 & 94,1 & 5,9 & 100 & 0 \\
\hline \multicolumn{5}{|c|}{ Malus sieboldii x 60-160 } \\
\hline 1 (control) & 92,9 & 7,1 & 100 & 0 \\
\hline 2 & 100 & 0 & & \\
\hline 3 & 54,5 & 45,5 & 80 & 20 \\
\hline \multicolumn{5}{|c|}{ Malus sieboldii x 76-3-6 } \\
\hline 1 (control) & 30,8 & 69,2 & 0 & 100 \\
\hline 2 & 92,3 & 7,7 & 100 & 0 \\
\hline 3 & 92,3 & 7,7 & 100 & 0 \\
\hline
\end{tabular}

Note: the most effective options are highlighted in bold

As a result of using different methods of sterilization, it was found that additional treatment with «Ecocid $\mathrm{C}$ » and «BioPag $\mathrm{C}$ » promotes the production of sterile explants from $7.1 \%$ to $61.5 \%$ in comparison with the control. The best option for the use of these antimicrobial agents was identified in a combination of $M$. sieboldii x 76-3-6 (Table 1).

Since the mother plant in all crossing combinations was the same genotype, the morphological and biochemical characteristics of the fruits were also the same for the development and accumulation of exo- and endogenous infections. As a result of evaluating the 
sterilization of explants in all combinations of crossing, it was possible to confirm the effectiveness of the proposed schemes (Table 2, Fig. 1). The best results were obtained when combine using «Ecocid $\mathrm{C} »(1.0 \%, 50 \mathrm{~min}$.$) and «Belizna» (50 \%, 5 \mathrm{~min})$.

Table 2. Effectiveness of the sterilization option

\begin{tabular}{|c|c|c|}
\hline Sterilization option & Sterile explants, $\%$ & Infected explants, $\%$ \\
\hline 1 (control) & 60,5 & 39,5 \\
\hline 2 & 95,2 & 4,8 \\
\hline 3 & 85,4 & 14,6 \\
\hline
\end{tabular}

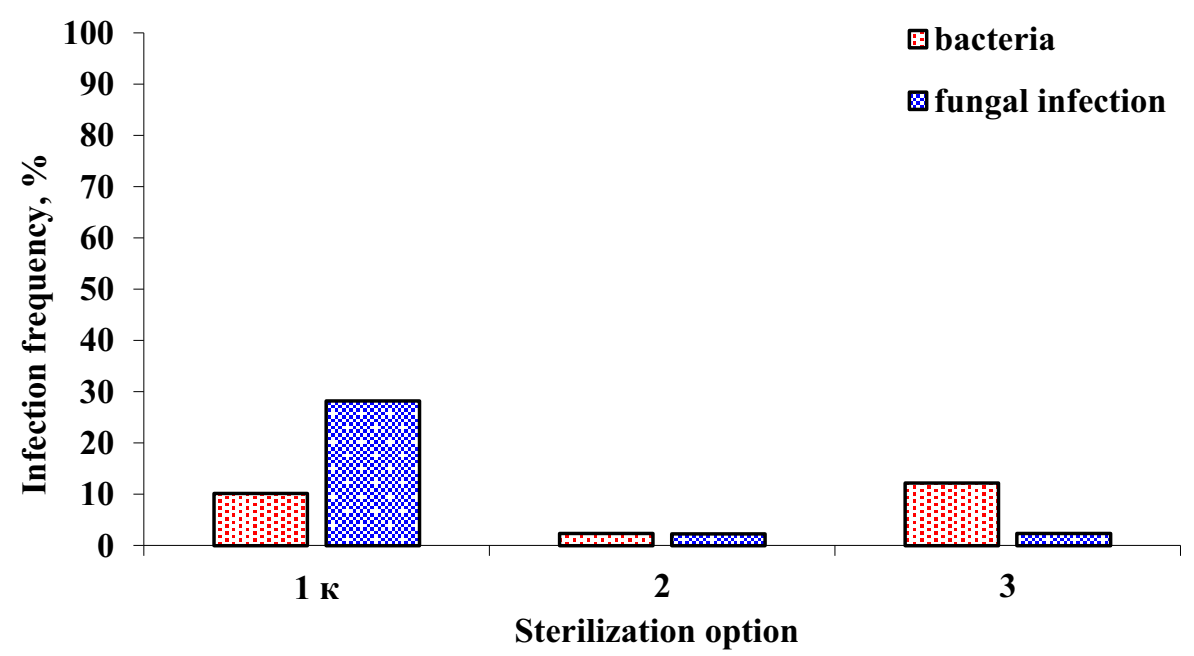

Fig. 1. The level of bacterial and fungal infection of the total number of explants

When using «Ecocid $\mathrm{C}$ » Ecocid $\mathrm{C}$ as a pretreatment, the infection rate is $2.4 \%$ bacterial and $2.3 \%$ fungal infection (Fig. 1). BioPag reduces bacterial and fungal infection to $12.2 \%$ and $2.4 \%$, respectively.

After 28 days, only $4.6 \%$ germinated from all hybrid seeds - in cross M. sieboldii $\mathrm{x}$ Malysh Budagovskogo. In this connection, a dissection method was applied, which can stimulate the development of the embryo, due to the better supply of nutrients from the artificial nutrient medium.

Sterile seeds began to germinate at 4 days after dissection (Fig. 2 c, d). In some cases, only a root or shoot was formed, but then, within 2-3 weeks, a full-fledged microplant was formed.

Since one of the research tasks is to obtain red-leaved «marker» hybrid genotypes, then these forms were selected at the stage of germination and development of embryos. Thus, at the initial stages of seed development, it was possible to fix a pigmented root (Fig. $2 \mathrm{f}$ ) or, in some cases, callus tissue (Fig. 2 g, h). 


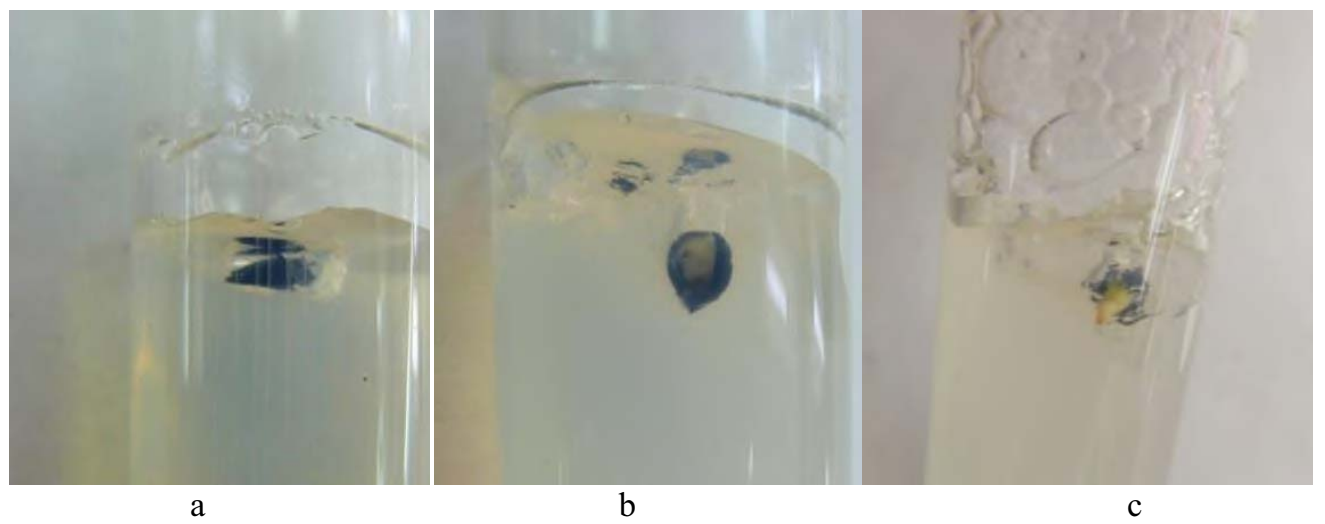

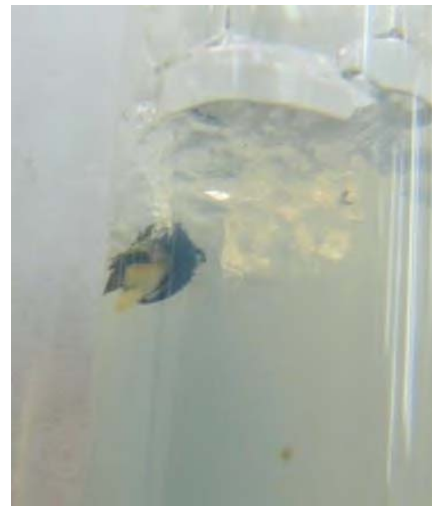

d

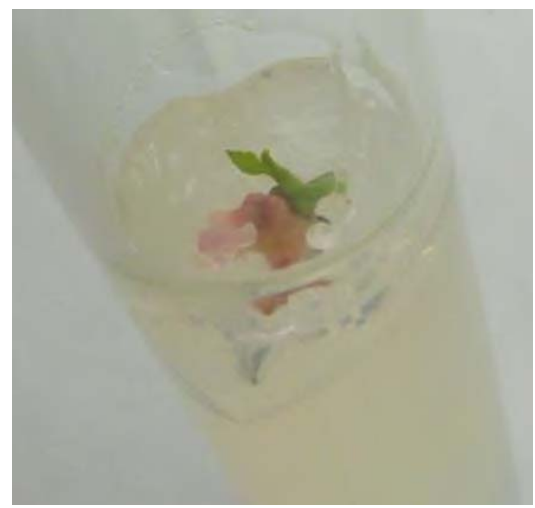

g
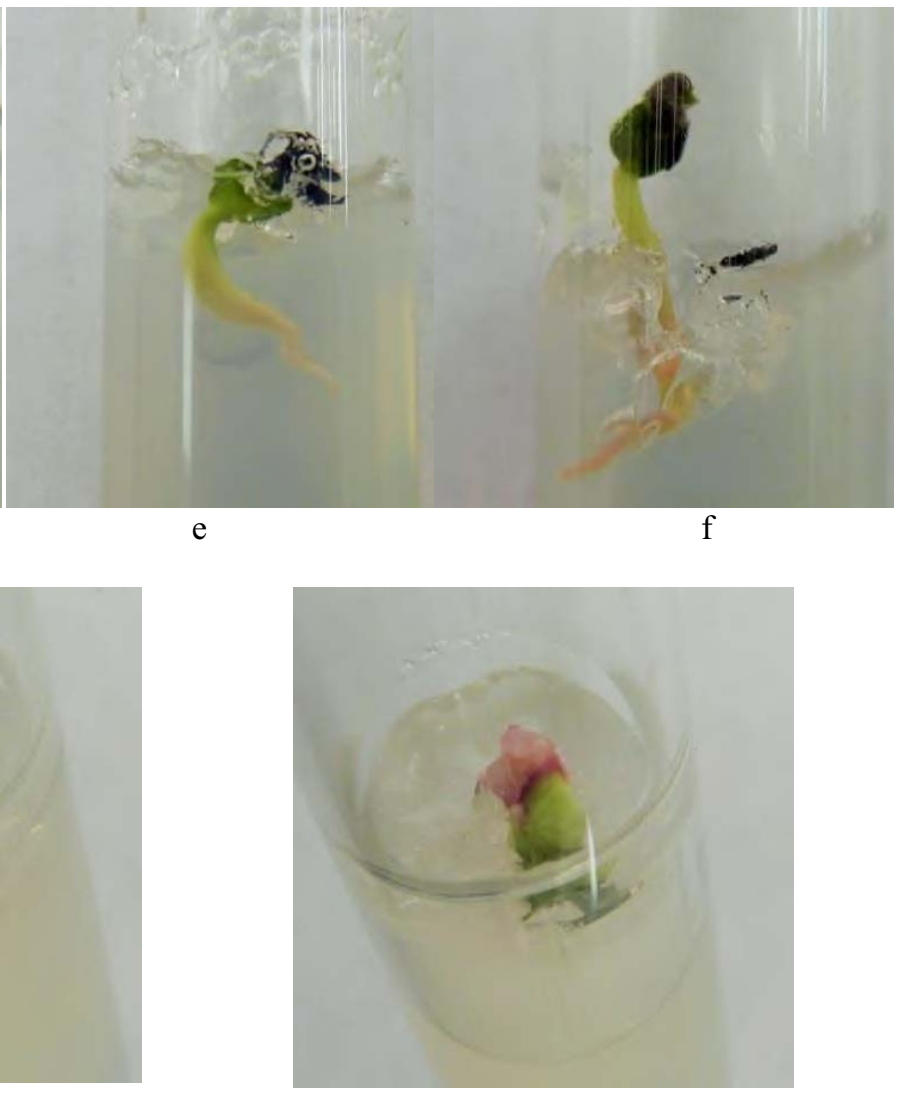

$\mathrm{h}$

Fig. 2. Development of hybrid embryos on artificial nutrient medium after dissection of cotyledons: a, $\mathrm{b}$ - seeds after cutting off the distal part of the cotyledons; $\mathrm{c}, \mathrm{d}$ - germinating seeds; $\mathrm{e}, \mathrm{f}-$ the formation of roots; $\mathrm{g}, \mathrm{h}-$ the formation of pigmented callus.

After 14 days of cultivation of seeds after dissection of cotyledons, it was found that this method allows obtaining up to $65.3 \%$ of hybrid plants (maximum in the combination of M. sieboldii x Malysh Budagovsky) (Fig. 3). Germinated seeds without dissection served as control (4.2\%). The smallest number of developing embryos was noded in the combination M. sieboldii x 76-3-6 (55.0\%), with complete absence of development in the control (Fig. 2 
$a, b)$.

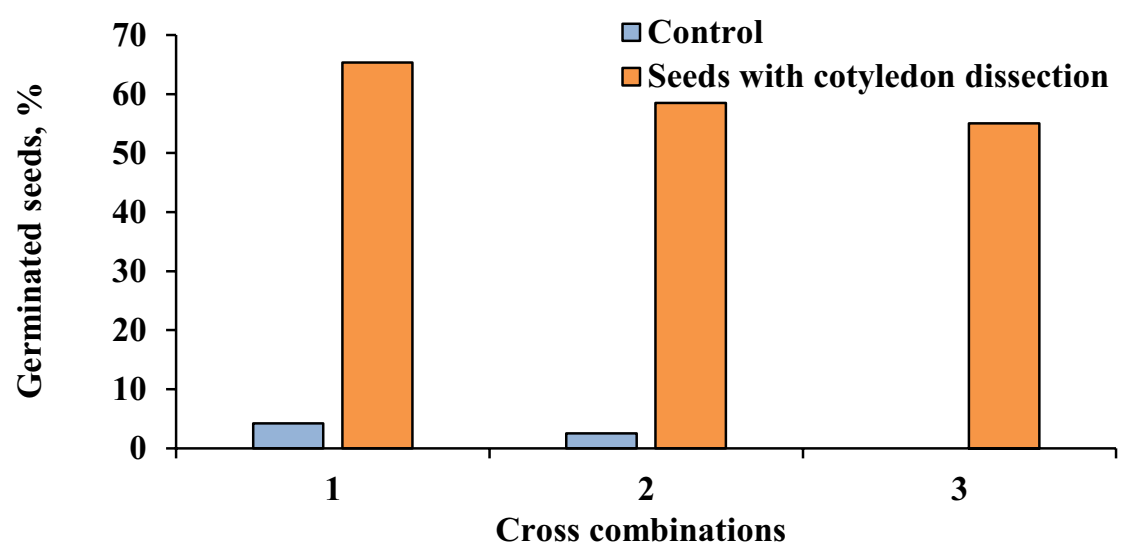

Fig. 3. Germination of hybrid seeds in different combinations at in vitro conditions after removing a part of the cotyledons: $1-$ M. sieboldii x Malysh Budagovskogo; $2-$ M. sieboldii x 60-160;3-M. sieboldii $\mathrm{x}$ 76-3-6

Analysis of the obtained hybrid plants for the trait of the leaf plate color showed that the cleavage in all three crosses was 1:1 (with anthocyanin coloration / without anthocyanin coloration) (Fig. 4).

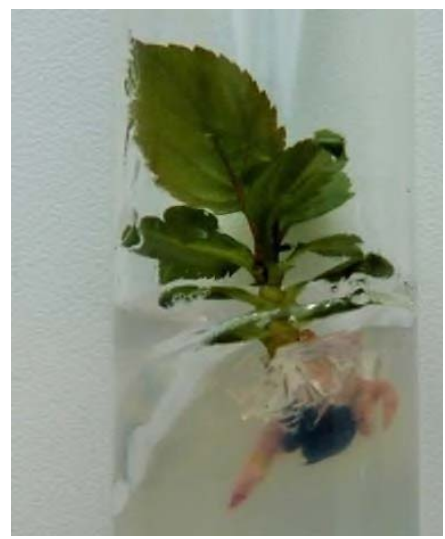

$\mathrm{a}$

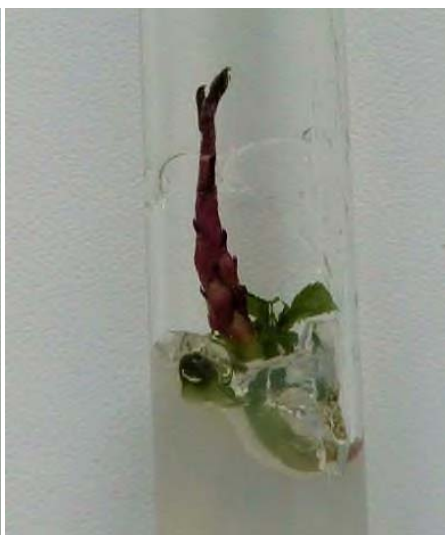

b

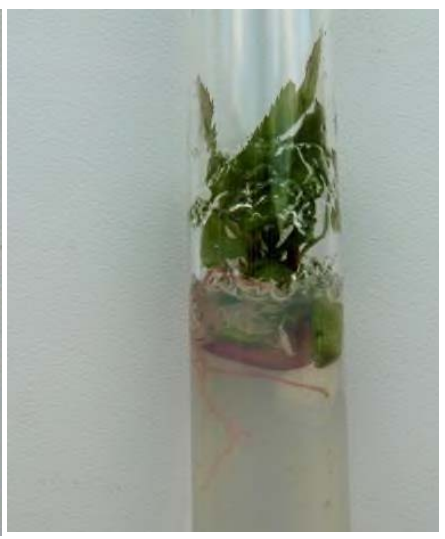

$\mathrm{c}$ 


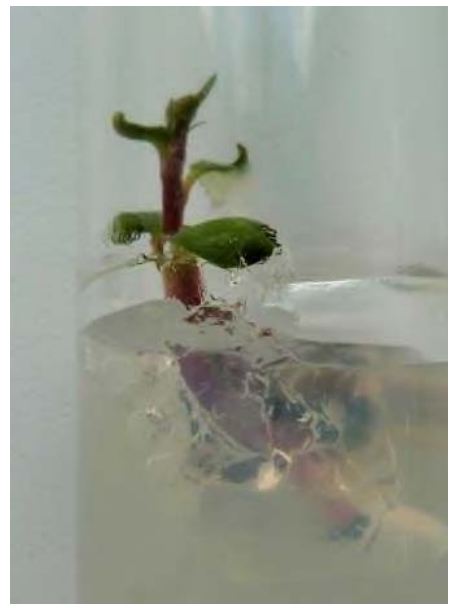

d

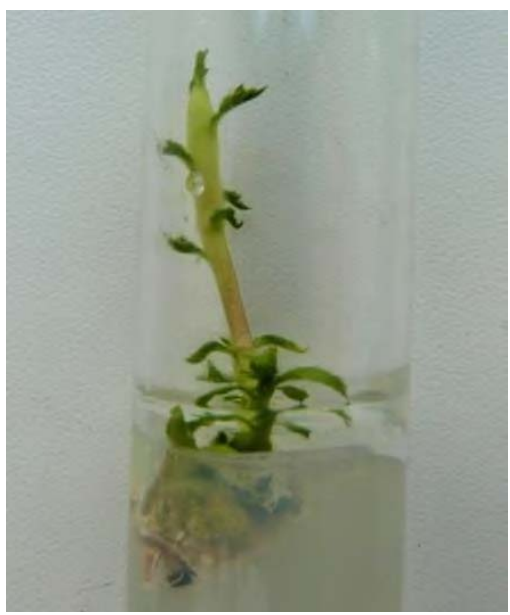

g

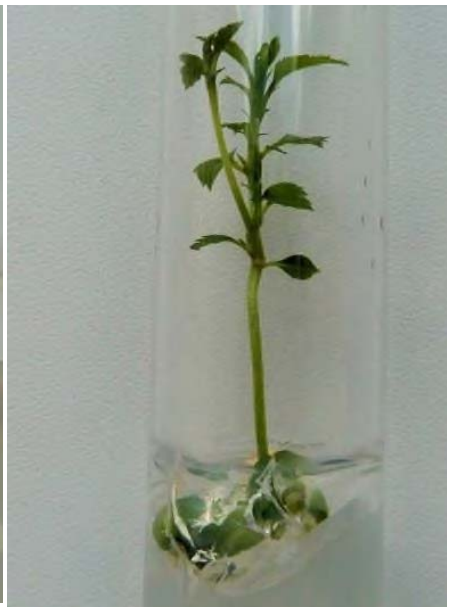

e

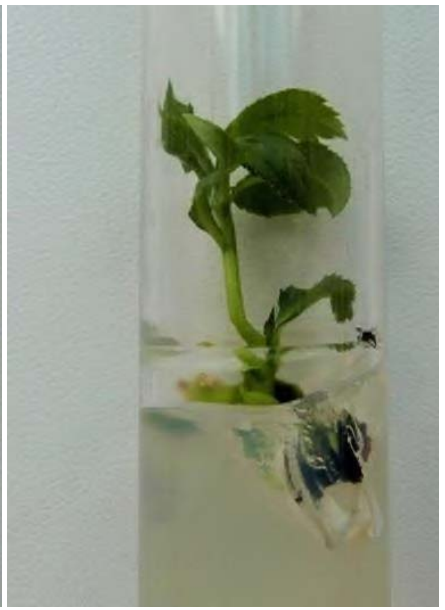

f

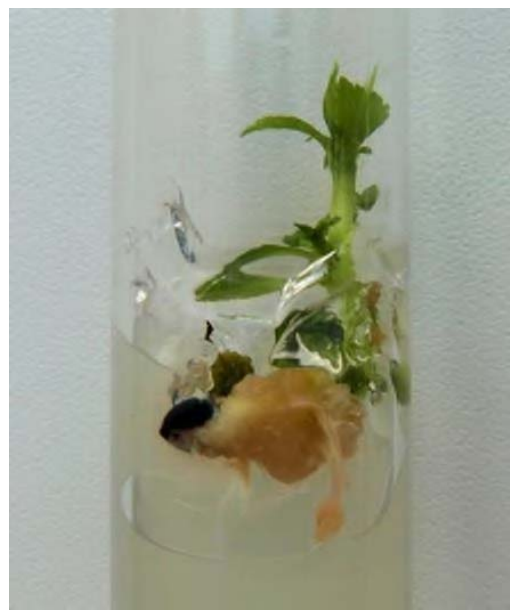

$\mathrm{h}$

Fig. 4. Development of hybrid Malus sieboldii plants with roots and shoots on the $20^{\text {th }}$ day after dissection of cotyledons: a-d - red-leaved forms; e-g - green-leaved forms

\section{Conclusions}

Thus, it was found that additional pretreatment with «Ecocid C» $(1.0 \%)$ and «BioPag C» $(0.4 \%)$ for 50 minutes promotes the production of sterile explants up to $61.5 \%$ compared to the control.

The use of dissection of cotyledons in seeds makes it possible to obtain up to $65.3 \%$ of hybrid plants compared to $4.2 \%$ with the control.

Splitting of hybrid seeds in cross combinations of $M$. sieboldii x Malysh Budagovskiy, M. sieboldii $\mathrm{x}$ 60-160, M. sieboldii x 76-3-6 by the anthocyanin coloration is $1: 1$.

The studies were carried out on the basis of the Center for Collective Use «Selection of agricultural crops and technologies for the production, storage and processing of food products for functional, therapeutic and prophylactic purposes» of the Michurinsky State Agrarian University within the framework of the State task of the Ministry of Agriculture of the Russian Federation «Increasing the 
efficiency of the adaptive potential of microplants of garden crops by stimulating the process rhizogenesis of micro-cuttings and the use of biologically active agents in protected ground conditions» for 2020.

\section{References}

1. G.M. Volk, A.D. Henk, A. Baldo, G. Fazio, C.T. Chao, C.M.Richards, American Journal of Botany 102, 1198 (2015) doi.org/10.3732/ajb.1500095

2. A. Ignatov, A. Bodishevskaya, Wild Crop Relatives: Genomic and Breeding Resources 45 (2010), https://link.springer.com/chapter/10.1007/978-3-642-16057-8_3 (Last accessed 12.06.2020)

3. B. Liu, G. Liu, D. Wen, Frontiers in Plant Science 10, 1731 (2020) doi.org/10.3389/fpls.2019.01731

4. M.L. Dubrovsky, R.V. Papikhin, Revista Amazonia Investiga 8, 688 (2019) ttps://amazoniainvestiga.info/index.php/amazonia/article/view/157 (Last accessed 12.06.2020)

5. S.A. Muratova, R.V. Papikhin, J. Pharm. Sci. \& Res. 10, 2592 (2018) https://elibrary.ru/item.asp?id=38629036 (Last accessed 15.06.2020)

6. E. Seemüller, E. Kiss, S. Sule, B. Schneider, Bacteriology 100, 863 (2010) https://apsjournals.apsnet.org/doi/pdf/10.1094/PHYTO-100-9-0863 (Last accessed 17.06.2020)

7. A.M. Ciccotti, C. Bisognin, I. Battocletti, M. Deromedi, P. Bragagna, M. Filippi, Bulletin of insectology 64, $273 \quad$ (2011) https://openpub.fmach.it/handle/10449/20382\#.XxrHuoszbIU (Last accessed 19.06.2020)

8. E. Seemüller, J. Gallinger, W. Jelkmann, W. Jarausch, European Journal of Plant Pathology 151, 767 (2018) https://link.springer.com/article/10.1007/s10658-017-14125 (Last accessed 22.06.2020)

9. S.K. Naik, P.K. Chand, Plant Cell Reports 30, 707 (2011) https://link.springer.com/article/10.1007/s00299-010-0969-7 (Last accessed 02.07.2020)

10. S.A. Muratova, T.E. Bocharova, R.V. Papikhin, Vestnik MichGAU 1, 54 (2012) https://elibrary.ru/item.asp?id=18021339 (Last accessed 02.07.2020)

11. R. Papikhin, M. Dubrovsky, Advances in Intelligent Systems Research 167, 363 (2019) https://elibrary.ru/item.asp?id=38579192 (Last accessed 02.07.2020)

12. A.I. Kuzin, Yu.V. Trunov, A.V. Solovyev, Acta Horticulturae 1217, 343 (2018) https://www.researchgate.net/publication/329038199_Effect_of_fertigation_on_yield_ and_fruit_quality_of_apple_Malus_domestica_Borkh_in_highdensity_orchards_on_chernozems_in_Central_Russia (Last accessed 05.07.2020)

13. R.V. Papikhin, M.L. Dubrovsky, Journal of Pharmaceutical Sciences and Research 10, 2524

https://www.researchgate.net/publication/329031702_Cytological_features_of_male_g ametophyte_formation_from_distant_hybrids_pyrus_X_Malus_and_ribes_X_ accessed 12.07.2020)

14. L.V. Grigoreva, International Journal of Pharmaceutical Research 10, 632 (2018) https://www.scopus.com/record/display.uri?eid=2-s2.0$85062404186 \&$ origin $=$ resultslist\&sort $=$ plf$\mathrm{f} \& \mathrm{src}=\mathrm{s} \& \mathrm{nlo}=\& \mathrm{nl}=\& \mathrm{nls}=\& \mathrm{sid}=4 \mathrm{~b} 3 \mathrm{~d} 9658 \mathrm{~d} 427 \mathrm{dfd} 4352 \mathrm{f} 7 \mathrm{~b} 27 \mathrm{a} 406 \mathrm{eaf0} \& \mathrm{sot}=\mathrm{aff} \& \mathrm{sdt}=$ 
$\mathrm{a} \& \mathrm{sl}=54 \& \mathrm{~s}=\mathrm{AF}-$

ID\%28"Michurinsk+State+Agrarian+University"+60097367\%29\&relpos=39\&citeCnt

$=1 \&$ searchTerm $=($ Last accessed 12.07.2020)

15. O.B. Kuzichev, N.Y. Kuzicheva, Indian Journal of Science and Technology 9, 89804 (2016)

https://www.researchgate.net/publication/303377110_Innovative_Processes_in_Floricu lture_Current_Status_Problems_and_Prospects (Last accessed 14.07.2020) 